\title{
Multi-Strain Tropical Bacillus spp. as a Potential Probiotic Biocontrol Agent for Large-Scale Enhancement of Mariculture Water Quality
}

\author{
Wei Ren 1,2,3,4, Haiwu Wu2,3, Cong Guo ${ }^{2,3}$, Bingqing Xue ${ }^{2,3}$, Hao Long ${ }^{1,2,3,4}$, \\ Xiang Zhang ${ }^{1,2,3,4}$, Xiaoni Cai 1,2,3,4, Aiyou Huang ${ }^{1,2,3,4}$ and Zhenyu Xie ${ }^{1,2,3,4 *}$ \\ ${ }^{1}$ State Key Laboratory of Marine Resource Utilization in the South China Sea, Hainan University, Haikou, China, ${ }^{2}$ Hainan \\ Provincial Key Laboratory for Tropical Hydrobiology and Biotechnology, Hainan University, Haikou, China, ${ }^{3}$ College of Marine \\ Sciences, Hainan University, Haikou, China, ${ }^{4}$ Laboratory of Development and Utilization of Marine Microbial Resource, \\ Hainan University, Haikou, China
}

OPEN ACCESS

Edited by:

Yang-Chun Yong,

Jiangsu University, China

Reviewed by:

Wenyi Zhang,

Inner Mongolia Agricultural University,

China

Yonggang Yang

Guangdong Academy of Science,

China

Sunil Khare,

Indian Institute of Technology Delhi,

India

*Correspondence:

Zhenyu Xie

xiezyscuta@163.com

Specialty section:

This article was submitted to

Microbiotechnology,

a section of the journa

Frontiers in Microbiology

Received: 06 May 2021

Accepted: 09 July 2021

Published: 11 August 2021

Citation:

Ren W, Wu H, Guo C, Xue B, Long $H$, Zhang $X$, Cai $X$, Huang $A$ and

Xie Z (2021) Multi-Strain Tropical

Bacillus spp. as a Potential Probiotic

Biocontrol Agent for Large-Scale

Enhancement of Mariculture Water

Quality. Front. Microbiol. 12:699378.

doi: 10.3389/fmicb.2021.699378
Aquaculture is suffering from long-term water eutrophication in intensive models, whereas the knowledge of multi-strain/specie for improving water quality is extremely limited. Herein, we aimed to develop multi-strain tropical Bacillus spp. as a potential probiotic biocontrol agent for large-scale enhancement of mariculture water quality. Given the practical application, the optimum multi-strain tropical Bacillus spp. (B. flexus QG-3, B. flexus NS-4, and B. licheniformis XCG-6 with the proportion 5: 5: 4) as a probiotic biocontrol agent was screened and obtained, which effectively improved water quality by removing chemical oxygen demand (COD), ammonia-nitrogen, and nitrate and significantly inhibited Vibrio spp. even at relatively low bacterial concentrations $\left(10^{4} \mathrm{CFU} / \mathrm{ml}\right)$ in artificial feed wastewater and large-scale shrimp aquaculture ponds. More importantly, we found that the initial proportion of these three Bacillus sp. strains of multi-strain tropical Bacillus spp. markedly affected the final purification effects, whereas the initial concentration of that only influenced the purification rates at the early stage $(0$ $48 \mathrm{~h}$ ) instead of final purification effects. We reason that this multi-strain tropical Bacillus spp. as a good probiotic biocontrol agent could perform multiple actions, such as CODdegrading, nitrifying, denitrifying, and antagonistic actions, for large-scale enhancement of tropical aquaculture water. Additionally, the multi-strain tropical Bacillus spp. was safe for shrimp and could be stored for at least 240 days in spore form at room temperature. This multi-strain probiotic biocontrol agent may facilitate its adoption for further marine recirculating aquaculture system development and large-scale commercial application.

Keywords: multi-strain tropical Bacillus spp., probiotic biocontrol agent, marine recirculating aquaculture system, mariculture water quality, aquaculture wastewater

\section{INTRODUCTION}

Generating/recycling water/resources from wastewater instead of just treating wastewater has become one of the most popular worldwide trends ( $\mathrm{Lu}$ et al., 2019). Aquaculture contributed to about $44 \%$ of total fish production which is well-known as an important economic activity (Hamza et al., 2017), whereas wastewater from aquaculture is loaded with excessive organic matter, ammonia-nitrogen, and phosphorus, thereby causing a series of economic loss, establishment of antibiotic-resistant bacteria, and environmental problems, 


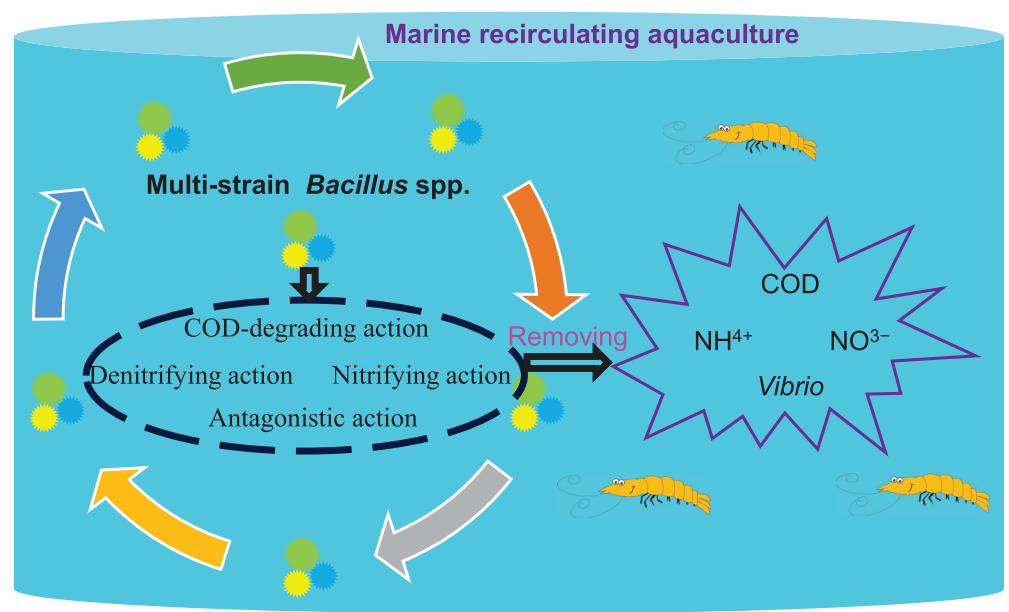

GRAPHICAL ABSTRACT | Multi-strain tropical Bacillus spp. as a potential probiotic biocontrol agent for large-scale enhancement of mariculture water quality.

such as water eutrophication and atmospheric pollution due to the volatilization of ammonia and hydrogen sulfide (Lin and Chen, 2001, 2003; Kuhn et al., 2010; Hai, 2015; Guo et al., 2016; Li et al., 2020; Mariane De Morais et al., 2020; Wei et al., 2021; Xu et al., 2021). Reportedly, the resistance of harmful pathogenic microorganisms in aquaculture was caused by the abuse of antibiotics and chemicals, and the drug residues from aquatic products posed serious threats to human health through stepwise enrichment of food chains (Vaseeharan and Ramasamy, 2003; Hai, 2015; Paopradit et al., 2021; Wei et al., 2021). Therefore, exploring a harmless and recyclable biotechnology for wastewater treatment is necessary to ensure the sustainable development of aquaculture and for environmental protection.

Furthermore, with the enhancement of awareness of quality and safety of aquatic products, the growing concern for antibiotic-resistant microorganisms has led to strategies of alternative disease prevention methods, such as the application of non-pathogenic bacteria as potential alternative biocontrol agents (Vaseeharan and Ramasamy, 2003; Dash et al., 2017; Wei et al., 2021). Microorganisms such as potential probiotic biocontrol candidates based on the principle of competitive exclusion and immune stimulants play critical roles in preventing diseases, improving water quality, increasing the quantity and quality of aquaculture animals, and serving as potential food sources for aquatic animals (Moriarty, 1997; Blancheton et al., 2013; Dash et al., 2017; Hucheng et al., 2020; Wei et al., 2021). Although many probiotic biocontrol candidates offer a promising alternative to chemical and antibiotics in aquaculture, a process of screening and optimizing probiotic biocontrol candidates for particular aquatic animals plays an important role to make them species specific (Verschuere et al., 2000; Sun et al., 2010; Sadat Hoseini Madani et al., 2018; Wei et al., 2021). Additionally, probiotic biocontrol candidates can perform well in favorable conditions created by appropriate administration methods, which have been worldwide used through water routine or feed additives with either single or a combination of probiotics or even a mixture with prebiotics (Van
Hai et al., 2007), thereby promoting enhancement of organic matter decomposition, reduction of nitrogen and phosphorus concentrations, and balance of ammonia, nitrite, and hydrogen sulfide (Boyd and Massaut, 1999; Ma et al., 2009; Cha et al., 2013).

Bacillus genera are commonly used in aquaculture, which can replace antibiotics and chemicals to prevent aquatic animal diseases and have no side effects on the aquaculture environment, thereby becoming a research hotspot of the processing of wastewater purification (Kuebutornye et al., 2019). Meanwhile, Bacillus genera were characterized by being rarely pathogenic and fast-growing and secreting high amounts of proteins, which were attractive species for the industry (Shah et al., 2016; Wei et al., 2021). Bacillus strains have been commonly selected as probiotics for humankind, applied in the aquaculture industry, mitigated nitrogen and phosphate pollution and a number of pathogenic bacteria, and especially associated with improving water quality by reducing organic matter accumulation (Rengpipat et al., 1998; Verschuere et al., 2000; Hai, 2015; Kumari et al., 2016; Saravanan et al., 2018; Sonune and Garode, 2018; Yi et al., 2018; Wang et al., 2019). Generally, Bacillus spp. are Gram-positive bacteria, which are better converters of organic matter back to $\mathrm{CO}_{2}$ than that of Gram-negative bacteria, thereby minimizing the buildup of dissolved and particulate organic carbon (Kuebutornye et al., 2019). However, most studies on Bacillus spp. focused on the use of single culture (Zokaeifar et al., 2014; Barman et al., 2018; De et al., 2018), while it is largely speculative whether two or even multiple combinations of strains/species would be beneficial. Reportedly, multi-strain/specie probiotics also enhanced protection against pathogenic infection (Timmerman et al., 2004; Kesarcodi-Watson et al., 2012).

We reason that Bacillus spp. based on a single strain are less effective than those based on multi-strain/specie probiotics in improving water quality. Therefore, the current research aimed to develop multi-strain tropical Bacillus spp. as a potential probiotic biocontrol agent for large-scale enhancement of mariculture water quality in shrimp aquaculture. The selected probiotic Bacillus spp. (Supplementary Figures 1, 2 and 
Supplementary Tables 1,2) from Hainan tropical mariculture systems stored at the State Key Laboratory of Marine Resource Utilization in the South China Sea exhibited strong potential probiotic candidates, since they displayed high activities of protease and lipase and effectively removed chemical oxygen demand (COD) and nitrogen. The optimum multi-strain tropical Bacillus spp. as a probiotic biocontrol agent was obtained through gradual optimization and screening in this work, which can effectively improve mariculture water quality. These results will provide useful and practical strategies for the marine recirculating aquaculture system to ensure the sustainable development of aquaculture and for environmental protection.

\section{MATERIALS AND METHODS}

\section{Microorganisms}

All tropical Bacillus strains used in this study, B. licheniformis XCG-1 and $B$. flexus NS-2 with COD removal efficiency, B. flexus QG-3 and B. flexus NS-4 with high lipase activity, $B$. licheniformis XCG-5 and B. licheniformis XCG-6 with high protease activity, and $B$. flexus XCG-7 and B. flexus XCG-8 with high removal ratio of nitrogen, were isolated from Hainan tropical mariculture systems and stored in the State Key Laboratory of Marine Resource Utilization in the South China. The eight Bacillus strains were identified by morphological observation (Supplementary Figure 1), phylogenetic analysis (Supplementary Figure 2), and physiological biochemical character (Supplementary Tables 1, 2), of which B. flexus QG-3, $B$. flexus NS-4, and B. licheniformis XCG-6 were registered in GenBank with accession numbers MZ404488, MZ404489, and MZ404490, respectively. Additionally, the commercial probiotic biocontrol product (containing Bacillus subtilis, Lactobacillus acidilactici, photosynthetic bacteria, Thiobacillus, denitrifying bacteria, Actinomycetes, nitrogen-releasing compounds, bioenzymes, microelements, growth promoting factor, etc.; concentration of viable bacteria $\geq 10^{9} \mathrm{CFU} / \mathrm{g}$ ) used as positive control were purchased from Hainan Zhengqiang Biochemical Technology Development Co., Ltd., Hainan, China.

\section{Preparation of Artificial Feed Wastewater}

Artificial feed wastewater was as follows: $20 \mathrm{~g} / \mathrm{l}$ artificial diet (containing $2 \mathrm{~g} / \mathrm{l}$ eel powder and $0.4 \mathrm{~g} / \mathrm{l} \mathrm{kelp} \mathrm{powder),} 10 \mathrm{ml} / \mathrm{l}$ skimmed milk, and $10 \mathrm{ml} / \mathrm{l}$ olive oil emulsion. The initial concentrations of $\mathrm{COD}$, ammonia-nitrogen, nitrate, and $\mathrm{pH}$ in feed wastewater were adjusted to $720 \mathrm{mg} / \mathrm{l}, 76 \mathrm{mg} / \mathrm{l}, 62 \mathrm{mg} / \mathrm{l}$, and 7.0 by artificial diet, $\left(\mathrm{NH}_{4}\right)_{2} \mathrm{SO}_{4}, \mathrm{NaNO}_{3}$, and $\mathrm{NaOH}$, respectively. Then, the feed wastewater was filtered by a 0.22 $\mu \mathrm{m}$-pore-size filter to remove bacteria for further use. Artificial feed wastewater was used to optimize and screen the optimum multi-strain tropical Bacillus spp.

\section{Aquaculture Water and Breeding Management}

Aquaculture water from five late-stage Litopenaeus vannamei ponds was used to confirm the ability of enhancement of mariculture water quality by the optimum multi-strain tropical Bacillus spp. The experimental ponds and aquaculture management are shown in Table 1.

\section{Plackett-Burman Design}

Plackett-Burman design, an effective method for screening significant factors, involves a large number of factors affecting the process and relatively few runs (Asfaram et al., 2016; Venkataraghavan et al., 2020). In this part of the study, PlackettBurman design was carried out to investigate the effect degrees of independent variables (B. licheniformis XCG-1, B. flexus NS-2, B. flexus QG-3, B. flexus NS-4, B. licheniformis XCG5 , B. licheniformis XCG-6, B. flexus XCG-7, and B. flexus $\mathrm{XCG}-8$ ) on COD removal efficiency in the process of artificial feed wastewater purification, and to screen some important Bacillus spp. strains for further optimization. Twelve groups of experiments with triplicates for each group were designed with eight Bacillus spp. strains (B. licheniformis XCG-1, B. flexus

TABLE 1 | Late-stage L. vannamei ponds and aquaculture management.

\begin{tabular}{|c|c|c|c|c|c|}
\hline & \multicolumn{5}{|c|}{ Late-stage $L$. vannamei ponds } \\
\hline & $1^{\#}$ & $2^{\#}$ & $3^{\#}$ & $4^{\#}$ & $5^{\#}$ \\
\hline Size $\left(m^{2}\right)$ & 2,800 & 3,133 & 3,000 & 2,600 & 2,533 \\
\hline $\begin{array}{l}\text { Water } \\
\text { depth }(m)\end{array}$ & 1.8 & 1.8 & 1.9 & 1.6 & 1.8 \\
\hline $\begin{array}{l}\text { Healthy } \\
\text { condition of } \\
\text { L. vannamei }\end{array}$ & $\begin{array}{l}\text { Unhealthy } \\
\text { oi }\end{array}$ & Unhealthy & Unhealthy & Healthy & Healthy \\
\hline $\begin{array}{l}\text { Vibrio } \\
\text { (CFU/ml) }\end{array}$ & 400 & 500 & 470 & 150 & 160 \\
\hline $\mathrm{COD}(\mathrm{mg} / \mathrm{l})$ & 72 & 121.5 & 73.5 & 42 & 20.5 \\
\hline $\mathrm{DO}(\mathrm{mg} / \mathrm{l})$ & 6.28 & 5.15 & 5.1 & 5.75 & 6.38 \\
\hline $\begin{array}{l}\text { Ammonia- } \\
\text { nitrogen } \\
(\mathrm{mg} / \mathrm{l})\end{array}$ & 2.1 & 3.15 & 2.98 & 1.12 & 1.08 \\
\hline $\begin{array}{l}\text { Nitrites } \\
(\mathrm{mg} / \mathrm{ll})\end{array}$ & 0.01 & 0.05 & 0.05 & 0.005 & 0.005 \\
\hline $\begin{array}{l}\text { Nitrates } \\
(\mathrm{mg} / \mathrm{l})\end{array}$ & 0.95 & 1.75 & 1.72 & 0.5 & 0.5 \\
\hline $\begin{array}{l}\text { Water } \\
\text { exchange } \\
(\mathrm{t} / \mathrm{d})\end{array}$ & 0 & 0 & 0 & 0 & 0 \\
\hline $\begin{array}{l}\text { Feed intake } \\
(\mathrm{kg} / \mathrm{d})\end{array}$ & 6 & 6 & 6 & 6 & 6 \\
\hline $\begin{array}{l}\text { Other } \\
\text { probiotics }\end{array}$ & No & No & Yes & No & No \\
\hline Treatment & $\begin{array}{c}\text { Multi-strain } \\
\text { Bacillus } \\
\text { spp. }\end{array}$ & $\begin{array}{l}\text { Multi-strain } \\
\text { Bacillus } \\
\text { spp. }+30 \% \\
\text { sugarcane } \\
\text { molasses }\end{array}$ & $\begin{array}{c}\text { Commercial } \\
\text { probiotic } \\
\text { biocontrol } \\
\text { product }\end{array}$ & $\begin{array}{c}30 \% \text { sugarcane } \\
\text { molasses }\end{array}$ & Control \\
\hline
\end{tabular}

Late-stage L. vannamei ponds with the treatment of commercial probiotic biocontrol product ( $3^{\#}$ pond) and without adding multi-strain tropical Bacillus spp. or $30 \%$ sugarcane molasses ( $5^{\#}$ pond) were as positive control and negative control, respectively. The initial concentrations of multi-strain tropical Bacillus spp. (B. flexus QG-3, B. flexus NS-4, and B. licheniformis XCG-6 with the proportion 5: 5: 4) and commercial probiotic biocontrol product in the treatment aquaculture ponds were adjusted to $10^{4} \mathrm{CFU} / \mathrm{ml}$. 
NS-2, B. flexus QG-3, B. flexus NS-4, B. licheniformis XCG-5, B. licheniformis XCG-6, B. flexus XCG-7, and B. flexus XCG8 ) by 12 -factor-2-level Plackett-Burman design for selecting the significant parameters. The experimental design and results used in this study are shown in Table 2. The COD removal efficiency (\%) after treating for $24 \mathrm{~h}$ was taken as the dependent or response. COD was detected by a Hach $\mathrm{DR} / 2400$ spectrophotometer $\left(\mathrm{HACH}^{\circledR}\right.$ Company, Loveland, CO., United States).

\section{The Path of Steepest Ascent}

The path of steepest ascent was applied to approach the optimal level of the significant variables. Actually, the concentration of each main effect factor (Bacillus sp.) obtained from the PlackettBurman design was far from the actual optimum. The significant factors should be roughly optimized to determine the center point of each variable for the next Box-Behnken design (Vi et al., 2017). Therefore, six runs with the response as the COD removal efficiency of feed wastewater were evaluated with triplicates for each run by the path of steepest ascent after treating for $24 \mathrm{~h}$ (Table 3 ).

\section{Box-Behnken Design}

Using the path of steepest ascent design, the significant factors were roughly optimized to determine the center points of each variable for Box-Behnken design. Box-Behnken was employed to provide the optimum levels of the three variables (X3, B. flexus QG-3; X4, B. flexus NS-4; X6, B. licheniformis XCG-6). Fifteen runs with three replications at the center points were conducted to determine the relationship of variance and approach the maximum response (COD removal efficiency at $24 \mathrm{~h}$ after treatment; Table 4). The regression and graphical analyses of the experimental data were analyzed and generated by the "Design Expert" statistical package (Design-Expert Software Version 12.0.3.0, Stat-Ease Inc., Minneapolis, MN, United States). The quality of the fit of quadratic model was expressed by the coefficient of determination $\left(R^{2}\right)$, and its statistical significance was checked by the $F$-test. The behavior of the system is explained by the following quadratic equation:

$$
Y=\beta_{0}+\sum_{\mathrm{i}=1}^{8} \beta_{\mathrm{i}} X_{\mathrm{i}}+\sum_{\mathrm{i}=1}^{8} \beta_{\mathrm{ii}} X_{\mathrm{i}}^{2}+\sum_{\mathrm{i}=1}^{7} \sum_{\mathrm{j}=\mathrm{i}+1}^{8} \beta_{\mathrm{ij}} X_{\mathrm{i}} X_{\mathrm{j}}+\varepsilon .
$$

\section{Verification}

\section{Large-Scale Production of Multi-Strain Tropical Bacillus spp.}

Bacillus spp. culture medium developed by our lab (containing $10 \mathrm{~g} / \mathrm{l}$ sugarcane molasses, $8 \mathrm{~g} / \mathrm{l}$ rice bran, $2 \mathrm{~g} / \mathrm{l}$ corn flour, $2 \mathrm{~g} / \mathrm{l} \mathrm{K}{ }_{2} \mathrm{HPO}_{4}, 0.05 \mathrm{~g} / \mathrm{l} \mathrm{MnSO} 4 \cdot \mathrm{H}_{2} \mathrm{O}$, and $0.1 \mathrm{~g} / \mathrm{l} \mathrm{MgSO} 4 \cdot 7 \mathrm{H}_{2} \mathrm{O}$; $\mathrm{pH}$ 7.0) was used for large-scale fermentation of $B$. flexus QG-3, B. flexus NS-4, and B. licheniformis XCG-6 in a 5001 stirred-tank fermenter (fermentation conditions: aeration rate $1.5 \mathrm{vvm}$, tank pressure 0.03-0.05 $\mathrm{MPa}$, agitation speed $90 \mathrm{rpm}$, temperature $30^{\circ} \mathrm{C}$ ), respectively. After individual fermentation for $36 \mathrm{~h}$, the fermentation broth of B. flexus QG-3, B. flexus NS-4, and $B$. licheniformis XCG-6 were separately put into
TABLE 2 | Twelve runs with 8 parameters in Plackett-Burman design.

\begin{tabular}{|c|c|c|c|c|c|c|c|c|c|}
\hline \multirow[t]{2}{*}{ Run \# } & \multicolumn{8}{|c|}{ Factor } & \multirow{2}{*}{$\begin{array}{l}\text { COD removal } \\
\text { efficiency (\%) }\end{array}$} \\
\hline & $X 1$ & $\mathrm{X} 2$ & X3 & $X 4$ & $\times 5$ & $\mathrm{x} 6$ & $\mathbf{X 7}$ & X8 & \\
\hline 1 & 1 & -1 & -1 & -1 & 1 & -1 & 1 & 1 & $40.58 \pm 1.42$ \\
\hline 2 & -1 & -1 & -1 & 1 & -1 & 1 & 1 & -1 & $46.11 \pm 0.69$ \\
\hline 3 & -1 & 1 & -1 & 1 & 1 & -1 & 1 & 1 & $40.08 \pm 1.48$ \\
\hline 4 & -1 & -1 & 1 & -1 & 1 & 1 & -1 & 1 & $58.82 \pm 1.50$ \\
\hline 5 & 1 & 1 & -1 & -1 & -1 & 1 & -1 & 1 & $50.14 \pm 1.63$ \\
\hline 6 & -1 & 1 & 1 & 1 & -1 & -1 & -1 & 1 & $61.96 \pm 2.33$ \\
\hline 7 & 1 & -1 & 1 & 1 & 1 & -1 & -1 & -1 & $59.91 \pm 0.97$ \\
\hline 8 & 1 & -1 & 1 & 1 & -1 & 1 & 1 & 1 & $69.62 \pm 1.66$ \\
\hline 9 & -1 & -1 & -1 & -1 & -1 & -1 & -1 & -1 & $22.22 \pm 1.59$ \\
\hline 10 & 1 & 1 & 1 & -1 & -1 & -1 & 1 & -1 & $55.79 \pm 0.96$ \\
\hline 11 & 1 & 1 & -1 & 1 & 1 & 1 & -1 & -1 & $53.79 \pm 1.72$ \\
\hline 12 & -1 & 1 & 1 & -1 & 1 & 1 & 1 & -1 & $59.91 \pm 1.36$ \\
\hline
\end{tabular}

eight parameters (Bacillus spp. strains) were shown as code levels. $X 1$, B. licheniformis XCG-1; X2, B. flexus NS-2; X3, B. flexus QG-3; X4, B. flexus NS4 ; X5, B. licheniformis XCG-5; X6, B. licheniformis XCG-6; X7, B. flexus XCG-7; $X 8$, B. flexus XCG-8. The selections of low (-1) and high (1) levels for each factor represent that the concentration of a single strain was set at $2 \times 10^{5} \mathrm{CFU} / \mathrm{ml}$ and $0 \mathrm{CFU} / \mathrm{ml}$, respectively, which was based on the results of pre-experiment.

TABLE 3 | Experimental design and results of the path of steepest ascent.

\begin{tabular}{|c|c|c|c|c|}
\hline \multirow[t]{2}{*}{ Run \# } & \multicolumn{3}{|c|}{ Factor (x $\left.10^{5} \mathrm{CFU} / \mathrm{ml}\right)$} & \multirow{2}{*}{$\begin{array}{l}\text { COD removal } \\
\text { efficiency (\%) }\end{array}$} \\
\hline & X3 & $\mathrm{X} 4$ & $\mathrm{X} 6$ & \\
\hline 1 & 2.0 & 2.0 & 2.0 & $63.50 \pm 1.48$ \\
\hline 2 & 3.0 & 2.7 & 2.6 & $64.94 \pm 0.92$ \\
\hline 3 & 4.0 & 3.4 & 3.2 & $70.88 \pm 2.06$ \\
\hline 4 & 5.0 & 4.1 & 3.8 & $75.13 \pm 1.38$ \\
\hline 5 & 6.0 & 4.8 & 4.4 & $72.50 \pm 0.88$ \\
\hline 6 & 7.0 & 5.5 & 5.0 & $71.19 \pm 0.75$ \\
\hline
\end{tabular}

X3, B. flexus QG-3; X4, B. flexus NS-4; X6, B. licheniformis XCG-6.

cans for further use (Supplementary Figure 3). The activities of proteinase and lipase in fermentation broth were detected using fat-free milk (Nygren et al., 2007) and rhodamine B (El Aamri et al., 2020), respectively. Bacterial suspension with the appropriate dilution gradient of multi-strain tropical Bacillus spp. obtained by large-scale fermentation was plated out on the Bacillus spp. culture medium agar plates and incubated overnight at $30^{\circ} \mathrm{C}$, and hence the total number of viable Bacillus spp. as colony-forming units (CFU)/ml existed in fermentation as CFU was obtained. Additionally, the evaluation of storage stability of mixed fermentation broth $\left(5.17 \times 10^{5} \mathrm{CFU} / \mathrm{ml}\right.$ B. flexus QG-3, $4.79 \times 10^{5} \mathrm{CFU} / \mathrm{ml}$ B. flexus NS-4, and $3.85 \times 10^{5} \mathrm{CFU} / \mathrm{ml}$ B. licheniformis XCG-6) was performed at room temperature for 240 days.

\section{Purification Effects of Multi-Strain Tropical Bacillus spp. on Artificial Feed Wastewater}

The optimum multi-strain tropical Bacillus spp. was $5.17 \times 10^{5} \mathrm{CFU} / \mathrm{ml} \mathrm{B}$. flexus QG-3, $4.79 \times 10^{5} \mathrm{CFU} / \mathrm{ml} B$. flexus NS-4, and $3.85 \times 10^{5} \mathrm{CFU} / \mathrm{ml} \mathrm{B}$. licheniformis XCG-6 
TABLE 4 | Fifteen runs with three parameters in Box-Behnken design.

\begin{tabular}{|c|c|c|c|c|}
\hline \multirow[t]{2}{*}{ Run \# } & \multicolumn{3}{|c|}{ Factor (x $\left.10^{5} \mathrm{CFU} / \mathrm{ml}\right)$} & \multirow{2}{*}{$\begin{array}{l}\text { COD removal } \\
\text { efficiency }(\%)\end{array}$} \\
\hline & X3 & X4 & X6 & \\
\hline 1 & 5 & 3.4 & 3.2 & $71.04 \pm 1.26$ \\
\hline 2 & 5 & 3.4 & 4.4 & $72.92 \pm 0.89$ \\
\hline 3 & 5 & 4.8 & 3.2 & $77.17 \pm 1.31$ \\
\hline 4 & 5 & 4.8 & 4.4 & $78.05 \pm 1.05$ \\
\hline 5 & 4 & 4.1 & 3.2 & $70.80 \pm 2.04$ \\
\hline 6 & 6 & 4.1 & 3.2 & $74.58 \pm 0.78$ \\
\hline 7 & 4 & 4.1 & 4.4 & $71.67 \pm 0.86$ \\
\hline 8 & 6 & 4.1 & 4.4 & $79.96 \pm 1.74$ \\
\hline 9 & 4 & 3.4 & 3.8 & $71.67 \pm 2.45$ \\
\hline 10 & 4 & 4.8 & 3.8 & $83.21 \pm 1.52$ \\
\hline 11 & 5 & 3.4 & 3.8 & $78.33 \pm 1.42$ \\
\hline 12 & 5 & 4.8 & 3.8 & $83.00 \pm 1.32$ \\
\hline 13 & 4 & 4.1 & 3.8 & $83.08 \pm 1.05$ \\
\hline 14 & 4 & 4.1 & 3.8 & $82.25 \pm 1.62$ \\
\hline 15 & 4 & 4.1 & 3.8 & $82.96 \pm 1.35$ \\
\hline
\end{tabular}

X3, B. flexus QG-3; X4, B. flexus NS-4; X6, B. licheniformis XCG-6.

$Y$ is the predicted response [COD removal efficiency (\%)], $\beta_{0}$ is the intercept, $\beta_{i}$ is the linear coefficient, $X_{i}$ is the factor variable coded, $\beta_{i i}$ is the quadratic coefficient for the factor, $\beta_{i j}$ is the interaction effect, and $\varepsilon$ is the error (Muhamad et al., 2013; Ren et al., 2016). The significance of all terms in the polynomial was judged statistically according to the p-value which was compared with the significance level of 0.05.

according to the results of optimization, indicating that $B$. flexus QG-3, B. flexus NS-4, and B. licheniformis XCG-6 in the proportion 5.17: 4.79: 3.85 (in theory) at the $10^{5} \mathrm{CFU} / \mathrm{ml}$ level as a potential probiotic biocontrol agent can effectively enhance the aquaculture wastewater quality. Given the practical application, the initial concentrations of multi-strain tropical Bacillus spp. (B. flexus QG-3, B. flexus NS-4, and B. licheniformis XCG-6 with the proportion 5: 5: 4) in 101 artificial feed wastewater were adjusted to $10^{4} \mathrm{CFU} / \mathrm{ml}, 10^{5} \mathrm{CFU} / \mathrm{ml}, 10^{6} \mathrm{CFU} / \mathrm{ml}, 10^{7} \mathrm{CFU} / \mathrm{ml}$, and $10^{8} \mathrm{CFU} / \mathrm{ml}$. Artificial feed wastewater without adding multi-strain tropical Bacillus spp. and that with commercial probiotic biocontrol product at the $10^{8} \mathrm{CFU} / \mathrm{ml}$ level were as negative control group and positive control group, respectively.

\section{Purification Effects of Multi-Strain Tropical Bacillus spp. on Mariculture Water}

Five late-stage L. vannamei ponds (Table 1) with the treatments of multi-strain Bacillus spp., multi-strain Bacillus spp. $+30 \%$ sugarcane molasses, $30 \%$ sugarcane molasses, commercial probiotic biocontrol product, and control without adding anything were used to confirm the ability of optimum multistrain tropical Bacillus spp. to improve mariculture water quality. Given the practical application, the initial concentrations of multi-strain tropical Bacillus spp. (B. flexus QG-3, B. flexus NS4 , and $B$. licheniformis XCG-6 with the proportion 5: 5: 4) and commercial probiotic biocontrol product in aquaculture ponds were adjusted to $10^{4} \mathrm{CFU} / \mathrm{ml}$. The concentrations of COD, ammonia-nitrite, and nitrate, as well as $\mathrm{pH}$ and the inhibition of Vibrio spp. in aquaculture ponds, were continuously detected during this experiment. Three parallel site samples with a uniform distribution from each pond were collected within $1 \mathrm{~m}$ of the shore at a depth of approximately $30 \mathrm{~cm}$ from the water surface.

For each sample, $\mathrm{pH}$ and DO (dissolved oxygen) were measured by a pH meter (AB15, Fisher Scientific, Waltham, MA, United States) and a DO tester (Oxi 3205SET3, WTW, Germany), respectively. COD, ammonia-nitrite, and nitrate were analyzed using a Hach DR/2400 spectrophotometer $\left(\mathrm{HACH}^{\circledR}\right.$ Company, Loveland, CO., United States). For the inhibition of Vibrio spp. detection, the inhibition ratio of the different treatments was calculated through the following equation:

$$
\text { Inhibition ratio }(\%)=[\mathrm{C}-\mathrm{T}] / \mathrm{C} \times 100 \%
$$

where $C$ is the initial number of Vibrio spp. (CFU/ml) in each pond as the control; $T$ is the number of Vibrio spp. (CFU/ml) at different periods after the treatments of multi-strain Bacillus spp., multi-strain Bacillus spp. + 30\% sugarcane molasses, 30\% sugarcane molasses, commercial probiotic biocontrol product, and the control without adding anything.

\section{RESULTS}

\section{Screening of Bacillus spp. Strains for Enhancement of Aquaculture Wastewater by Plackett-Burman Design}

The experiment design matrix with $Y$ (COD removal efficiency) as responses is listed in Table 1, and the results and analysis of variance (ANOVA) are presented in Table 5. After fitting a first-order polynomial model, the coefficient of determination $\left(R^{2}\right)$ was about 0.97 , which indicated a good fit. For the COD removal efficiency, three independent variables (X3, B. flexus QG3; X4, B. flexus NS-4; X6, B. licheniformis XCG-6) presented significantly positive effects (Table 5). Generally, the variable with a confidence level above 95\% $(p<0.05)$ is considered as a significant parameter. These results were confirmed from the Pareto chart as shown in Figure 1, indicating that higher effects presented in the upper portion and then progressed down to the lower effects. In addition, the "Adequacy precision" value of 13.73 for COD removal efficiency, greater than 4, demonstrated that the signal was adequate. Therefore, taking the COD removal efficiency, B. flexus QG-3, B. flexus NS-4, and B. licheniformis XCG-6 were selected as the important bacteria for further concentration optimization.

\section{Optimizing of Bacillus spp. Strains for Enhancement of Aquaculture Wastewater by Path of Steepest Ascent and Box-Behnken Design}

Based on the results of Plackett-Burman design, the most significant factors (B. flexus QG-3, B. flexus NS-4, and B. licheniformis XCG-6) were conducted in the path of steepest ascent. The experiment design and responses for the path of steepest ascent design are shown in Table 3. The highest COD removal efficiency $(75.13 \%)$ was reported at run 4 with 
TABLE 5 | ANOVA for 12-run Plackett-Burman design and model fitting.

\begin{tabular}{lcccccl}
\hline Source & $\begin{array}{c}\text { Sum of } \\
\text { squares }\end{array}$ & df & $\begin{array}{c}\text { Mean } \\
\text { square }\end{array}$ & F-value & $\begin{array}{c}\boldsymbol{P} \text {-value } \\
\text { (Prob }>\boldsymbol{F} \text { ) }\end{array}$ & \\
\hline Model & 1746.5500 & 8 & 218.3187 & 13.7325 & 0.0271 & Significant \\
X1 & 138.2444 & 1 & 138.2444 & 8.6957 & 0.0601 & \\
X2 & 49.65401 & 1 & 49.6540 & 3.1233 & 0.1753 & \\
X3 & 1065.7790 & 1 & 1065.7790 & 67.0388 & 0.0038 & Significant \\
X4 & 161.4067 & 1 & 161.4067 & 10.1527 & 0.0499 & Significant \\
X5 & 4.3802 & 1 & 4.3802 & 0.2755 & 0.6360 & \\
X6 & 278.8852 & 1 & 278.8852 & 17.5422 & 0.0248 & Significant \\
X7 & 2.2969 & 1 & 2.2969 & 0.1445 & 0.7292 & \\
X8 & 45.9034 & 1 & 45.9034 & 2.8874 & 0.1878 & \\
Residual & 47.6938 & 3 & 15.8979 & & & \\
Cor total & 1794.2440 & 11 & & & & \\
\hline
\end{tabular}

\section{Credibility analysis of the regression equations}

\begin{tabular}{lcccccc}
\hline Index mark & SD & Mean & CV\% & $R^{2}$ & Adj. $R^{2}$ & $\begin{array}{c}\text { Adequacy } \\
\text { precision } \\
\text { COD }\end{array}$ \\
3.99 & 51.58 & 7.73 & 0.97 & 0.90 & 13.73
\end{tabular}

removal

efficiency

(\%)

$X 1$, B. licheniformis XCG-1; X2, B. flexus NS-2; X3, B. flexus QG-3; X4, B. flexus NS-4; X5, B. licheniformis XCG-5; X6, B. licheniformis XCG-6; X7, B. flexus XCG-7; $X 8$, B. flexus XCG-8.

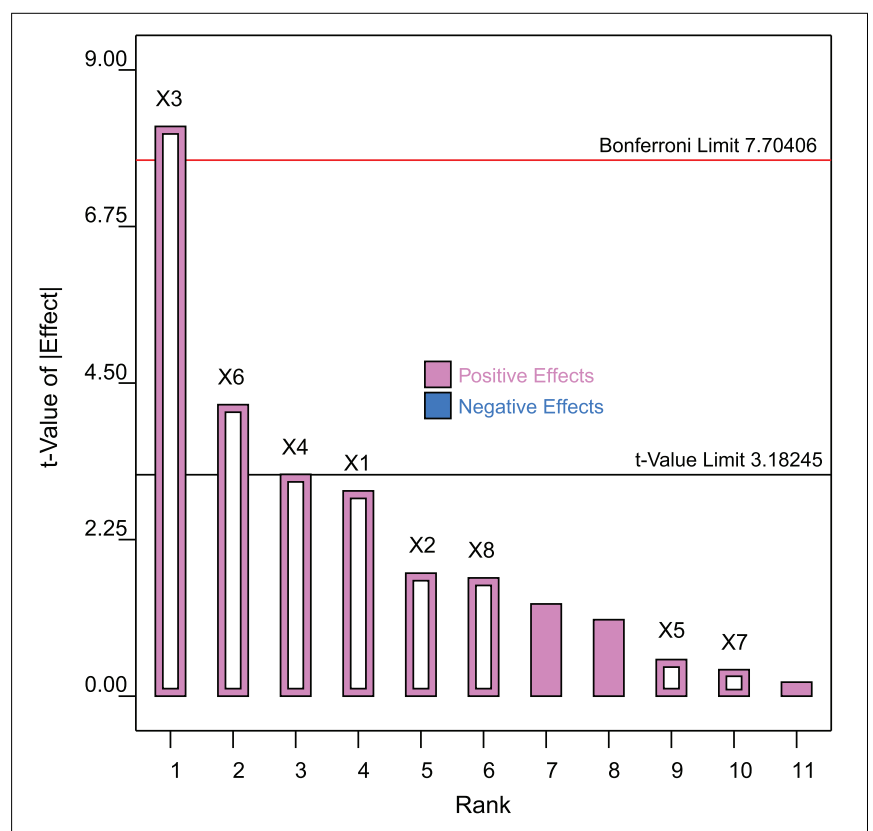

FIGURE 1 | Pareto chart showing the effect of Bacillus spp. strains. $X 1$, B. licheniformis XCG- 1 ; X2, B. flexus NS-2; X3, B. flexus QG-3; X4, B. flexus NS-4; X5, B. licheniformis XCG-5; X6, B. licheniformis XCG-6; X7, B. flexus XCG-7; X8, B. flexus XCG-8.

$5 \times 10^{5} \mathrm{CFU} / \mathrm{ml}$ B. flexus QG-3, $4.1 \times 10^{5} \mathrm{CFU} / \mathrm{ml}$ B. flexus NS4 , and $3.8 \times 10^{5} \mathrm{CFU} / \mathrm{ml}$ B. licheniformis XCG- 6 . The levels of three factors at run 4 were used in the optimization step through Box-Behnken design.
TABLE 6 | ANOVA for 15-run Box-Behnken design and model fitting.

\begin{tabular}{|c|c|c|c|c|c|c|}
\hline Source & $\begin{array}{l}\text { Sum of } \\
\text { squares }\end{array}$ & df & $\begin{array}{l}\text { Mean } \\
\text { square }\end{array}$ & $F$-value & $\begin{array}{c}\text { P-value } \\
(\text { Prob }>F)\end{array}$ & \\
\hline Model & 328.4645 & 9 & 36.4961 & 20.4212 & 0.0020 & Significant \\
\hline X3 & 42.8738 & 1 & 42.8738 & 23.9898 & 0.0045 & Significant \\
\hline$X 4$ & 94.3251 & 1 & 94.3251 & 52.7791 & 0.0008 & Significant \\
\hline X6 & 10.1475 & 1 & 10.1475 & 5.6780 & 0.0629 & \\
\hline$X 3 \times 4$ & 11.7992 & 1 & 11.7992 & 6.6022 & 0.0501 & \\
\hline$\times 3 \times 6$ & 5.0850 & 1 & 5.0850 & 2.8453 & 0.1524 & \\
\hline$\times 4 \times 6$ & 0.2500 & 1 & 0.2500 & 0.1400 & 0.7237 & \\
\hline$x 3^{2}$ & 16.6992 & 1 & 16.6992 & 9.3440 & 0.0282 & Significant \\
\hline$x 4^{2}$ & 9.2662 & 1 & 9.2662 & 5.1848 & 0.0718 & \\
\hline$x 6^{2}$ & 150.4895 & 1 & 150.4895 & 84.2056 & 0.0003 & Significant \\
\hline Residual & 8.9358 & 5 & 1.7872 & & & \\
\hline Lack of fit & 8.5334 & 3 & 2.8445 & 14.1351 & 0.0668 & Not significant \\
\hline Pure error & 0.4025 & 2 & 0.2012 & & & \\
\hline Cor total & 337.4003 & 14 & & & & \\
\hline \multicolumn{7}{|c|}{ Credibility analysis of the regression equations } \\
\hline Index mark & SD & Mean & CV\% & $R^{2}$ & Adj. $R^{2}$ & $\begin{array}{l}\text { Adequacy } \\
\text { precision }\end{array}$ \\
\hline $\begin{array}{l}\text { COD } \\
\text { removal } \\
\text { efficiency } \\
(\%)\end{array}$ & 1.34 & 77.38 & 1.73 & 0.97 & 0.93 & 12.00 \\
\hline
\end{tabular}

X3, B. flexus QG-3; X4, B. flexus NS-4; X6, B. licheniformis XCG-6.

Box-Behnken design was employed to optimize the key factors (X3, B. flexus QG-3; X4, B. flexus NS-4; X6, B. licheniformis XCG-6) and evaluate their interactions on the COD removal efficiency in the process of artificial feed wastewater purification. The combination of independent variables, results, and ANOVA are listed in Tables 4, 6. The statistical significance of each coefficient of regression equation was checked by Fisher's " $F$ statistics" value ( $F$-value) and probability value ( $p$-value), thus in turn indicating the interactions of the variables. Generally, the model with a very small $p$-value $(p<0.05)$ indicates that the model term is significant; meanwhile, the larger $F$-value and lower $P$-value indicate the significance of each term. From Table 6, the coefficients of linear term (X3, X4) and quadratic term $\left(\mathrm{X}^{2}{ }^{2}\right.$ and $\left.\mathrm{X} 6^{2}\right)$ were significant for COD removal efficiency. The results listed in Table 6 indicated that the models were significant and adequate for reasonable prediction of COD removal efficiency, within the variable range employed, as evidenced by the $F$-value (20.4212) and the low probability values (0.002). It also indicated that the chance for model $F$-values of this size occurred because of the statistical noise which was only $0.2 \%$. The "Lack of fit" test was used to measure the failure of the model to fit the experiment data. The "Lack of fit" gave $F$-values for COD removal efficiency of 14.1351 and $p$-values for the response of 0.0668 . The results suggested that the "Lack of fit" was non-significant relative to the pure error, with probabilities of $6.68 \%$ for occurrence for COD removal efficiency of this large value due to noise. The result indicated that the models could fit the experimental values and excellently predict COD removal efficiency. 
A higher coefficient of determination $\left(R^{2}\right)$ of the quadratic regression model indicates that the model is workable. Therefore, the $R^{2}$ of COD removal efficiency was 0.97 and the adjusted $R^{2}$ was 0.93 which were in reasonable agreement with $R^{2}$, demonstrating a high degree of correlations between the experimental data and predicted values. In general, a low coefficient of variation indicates that the model is adequate and owns high precision and reliability for fitting experimental values. In this case, the coefficient of variances (CV) for COD removal efficiency was 1.73 , which was low enough to represent the data adequately. In addition, the "Adequacy precision" value of 12 for COD removal efficiency, greater than 4 , demonstrating that the signal was adequate. The empirical equation developed for COD removal efficiency is listed as follows:

$$
\begin{aligned}
& Y=-343.51371+26.50048 \mathrm{X} 3+45.94566 \mathrm{X} 4 \\
& +129.69858 \mathrm{X} 6-2.45357 \mathrm{X} 3 \mathrm{X} 4 \\
& +1.87917 \mathrm{X} 3 \mathrm{X} 6-0.59524 \mathrm{X} 4 \mathrm{X} 6 \\
& -2.12667 \mathrm{X} 3^{2}-3.23299 \mathrm{X} 4^{2}-17.73380 \times 6^{2}
\end{aligned}
$$

In order to study and visualize the influences of factors and their mutual interactions on COD removal efficiency, three-dimensional (3D) response surfaces and two-dimensional (2D) response contours were plotted by the response ( $Z$-axis) according to two factors ( $X$ and $Y$ coordinates), holding the other one factor at zero (0 level). The interactions between $B$. flexus QG-3 (X3) and B. flexus NS-4 (X4) are presented in Figure 2A, keeping the concentration of $B$. licheniformis XCG-6 at 0 level. For COD removal efficiency, B. flexus QG-3 (X3) and flexus NS-4 (X4) contributed significant influences in a linear manner, while the interactive effects between each other presented nonsignificant effects. As the concentrations of B. flexus QG-3 and $B$. flexus NS-4 increased, the COD removal efficiency increased significantly and then decreased slightly. Figure 2B presents the interaction of B. flexus QG-3 (X3) and B. licheniformis XCG-6 (X6), with a fixed $B$. flexus NS-4 (0 level). The linear and quadratic terms of $B$. flexus QG-3 caused significant influences on COD removal efficiency, while $B$. licheniformis XCG- 6 only contributed significant influences in quadratic terms. Figure 2C shows the response surfaces of $B$. flexus NS-4 (X4) and B. licheniformis XCG-6 (X6), with a fixed B. flexus QG-3. The significant effects on COD removal efficiency were caused by the linear manner of B. flexus NS-4 and quadratic manner of B. licheniformis XCG-6, while the interactive effects $B$. flexus NS-4 and B. licheniformis XCG-6 produced non-significant influences on COD removal efficiency. All of the interactions of individual Bacillus sp. to each other presented non-significant effects (Table 6).

After optimization by Box-Behnken design, the predicted optimum multi-strain tropical Bacillus spp. was $5.17 \times 10^{5} \mathrm{CFU} / \mathrm{ml}$ B. flexus QG-3, $4.79 \times 10^{5} \mathrm{CFU} / \mathrm{ml} B$. flexus NS-4, and $3.85 \times 10^{5} \mathrm{CFU} / \mathrm{ml} B$. licheniformis XCG6 , respectively. Using this optimum multi-strain tropical Bacillus spp., the theoretical COD removal efficiency was found to about $84.70 \%$.

\section{Verification Test}

To confirm the validity of the statistical experimental strategies for large-scale application of wastewater purification, firstly, B. flexus QG-3, B. flexus NS-4, and B. licheniformis XCG-6 were separately obtained by large-scale cultivation (Supplementary Figure 3). In turn, the optimum multi-strain tropical Bacillus spp. (B. flexus QG-3, B. flexus NS-4, and B. licheniformis XCG6 in the proportion 5: 5: 4) and commercial probiotic biocontrol product (as the positive control) were used to treat artificial feed wastewater and aquaculture water of L. vannamei ponds.

As shown in Figure 3A, COD removal ratios of artificial feed wastewater displayed the rapidly increasing rate in a 24 -h period and then decreased slightly in a $24-48$-h period. The COD removal ratio of artificial feed wastewater reached a maximum (above 90\%) after treating with multi-strain tropical Bacillus spp. and commercial product in a 48 -h period, while COD content did not change significantly in the 48-96-h period. We reason that the organic matter of artificial feed wastewater was sufficient for microorganisms as nutrients for their own growth in the 48-h period. After $96 \mathrm{~h}$, with the depletion of organic matter in artificial feed wastewater, the dead bacteria and extracellular products led to COD content slightly increasing. Meanwhile, the trend of removal ratios of ammonia-nitrogen (Figure 3B) and nitrate (Figure 3C) was similar to that of COD in artificial feed wastewater, which indicated that these strains could not only effectively remove COD but also simultaneously remove ammonia-nitrogen and nitrate. The removal ratio of nitrate was up to the maximum in the 48 -h period, while that of ammonianitrogen reached the maximum at $72 \mathrm{~h}$. This delay may be due to that multi-strain tropical Bacillus spp. firstly promoted the organic matter decomposition, thereby resulting in accumulation of ammonia-nitrogen, and then conversion of ammonia-nitrogen to nitrite, whereas initial nitrate in wastewater was conversed immediately. Interestingly, the initial concentration of multistrain tropical Bacillus spp. almost did not influence the final results of purification effects, which only had the effect on the purification rate of treatment in the early stage $(0-48 \mathrm{~h})$. However, the initial proportion of B. flexus QG-3, B. flexus NS-4, and $B$. licheniformis XCG-6 in multi-strain tropical Bacillus spp. compared with the initial concentration of multi-strain tropical Bacillus spp. played a key role in the purification effects according to the results of optimization (Figure 3 ).

As shown in Figures $\mathbf{4 A}-\mathbf{C}$, the removal ratios of $\mathrm{COD}$, ammonia-nitrogen, and nitrate of aquaculture water of L. vannamei ponds displayed the rapidly increasing rate in the 24-h period and then decreased slightly in the 24-48-h period, which was similar to that of artificial feed wastewater, indicating that due to the rapid growth and reproduction of the strains, considerable amounts of nutrient salts and organic matter were used and degraded during this period. Meanwhile, DO of aquaculture water of L. vannamei ponds with the treatment of these bacteria maintained at a high level in the $24-48$-h period (Supplementary Figure 4), indicating that these Bacillus spp. were aerobic bacteria with low biochemical oxygen demand and would not compete for oxygen with aquaculture animals. In Figure 4D, with the growth and reproduction of Bacillus spp., the number of Vibrio spp. in ponds decreased continuously, 

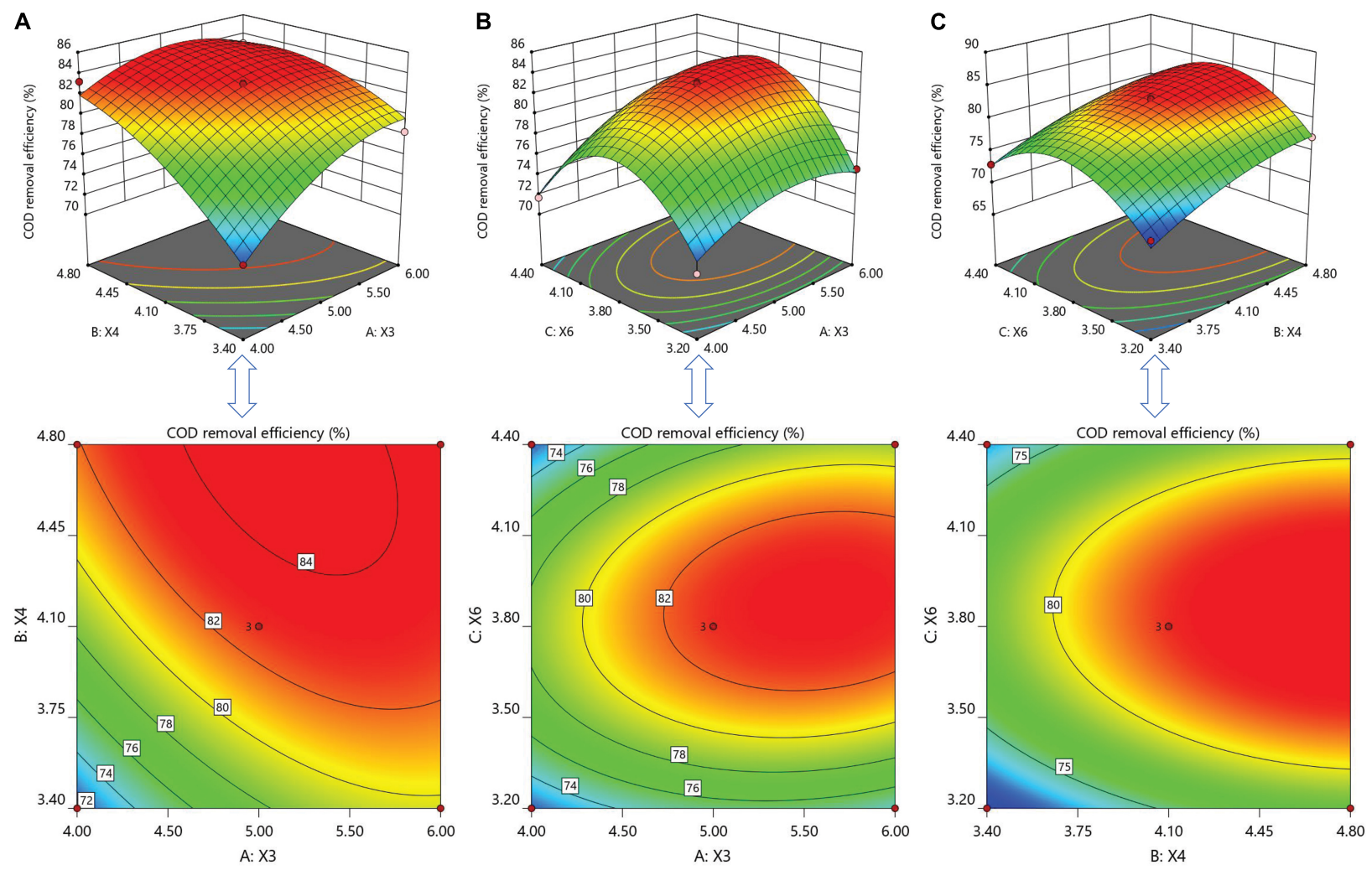

FIGURE 2 | Response surface and contour plots for the effect of variables on COD removal efficiency. (A) For the effect of A: B. flexus QG-3 (X3) and B: B. flexus NS-4 (X4); (B) for the effect of A: B. flexus QG-3 (X3) and C: B. licheniformis XCG-6 (X6); (C) for the effect of B: B. flexus NS-4 (X4) and C: B. licheniformis XCG-6 (X6).

indicating that these Bacillus spp. can effectively inhibit the growth and reproduction of Vibrio spp. in L. vannamei ponds by competition nutrition. The sugarcane molasses accelerated the removal ratios of COD, nitrate, and Vibrio of multi-strain Bacillus spp., whereas they did not influence their final purification effects (Figures 4A,B,D). Additionally, non-significant mortality was observed in every pond during the testing period, indicating that multi-strain Bacillus spp. was harmless to shrimp.

\section{Storage Stability of Multi-Strain Tropical Bacillus spp.}

The storage stability of multi-strain tropical Bacillus spp. was evaluated by monitoring the total number of viable bacteria, protease activity, and $\mathrm{pH}$ (Table 7). After 240 days, the total number of viable bacteria of multi-strain tropical Bacillus spp. was maintained above $10^{8} \mathrm{CFU} / \mathrm{ml}$ in spore form, $\mathrm{pH}$ decreased from 7.2 to 5.7, and protease activity was still maintained at a relatively high level, indicating that the multi-strain tropical Bacillus spp. can be stored for a long time at room temperature.

\section{DISCUSSION}

Currently, biological treatment as a harmless and recyclable technology for aquaculture wastewater treatment provides an eco-friendly method where microorganisms were added at certain concentrations to ensure the sustainable development of aquaculture instead of depending on only the freshwater source (Wei et al., 2021). As we all know, beneficial bacteria called probiotics give a much more efficient approach to alternate chemotherapeutic agents, which are sustainable aquaculture as well as being environment-friendly (Nimrat et al., 2012). Foremost among probiotics, photosynthetic bacteria (Chang et al., 2019; Lu et al., 2019), yeast (Gao et al., 2019), Lactobacillus spp. (Dawood et al., 2020; Zheng et al., 2020), and Pseudomonas spp. (Ruan et al., 2020; Zhang et al., 2020), especially Bacillus spp. (Barman et al., 2018; Gao et al., 2018), have advantages to the enhancement of aquaculture water quality. Bacillus as a potential probiotic biocontrol agent has been commonly chosen to improve water quality for sustainable aquaculture by reducing organic matter, ammonia-nitrogen, and phosphorus accumulation and inhibiting certain pathogenic bacteria of fishery by producing antimicrobial peptides, such as B. megaterium (Luo et al., 2016; Gao et al., 2018), B. cereus (Lalloo et al., 2007; Lalloo et al., 2010), B. subalis (Lalloo et al., 2007), and B. licheniformis (Lalloo et al., 2007), B. velezensis (Thurlow et al., 2019), whereas most of these literatures focused on a single probiotic bacterium for wastewater purification. We reason that a good probiotic biocontrol agent should have the capability of effectively removing multi-waste compounds from wastewater. Given this point, a consortium of probiotic bacteria will be advantageous over a single culture for improving 

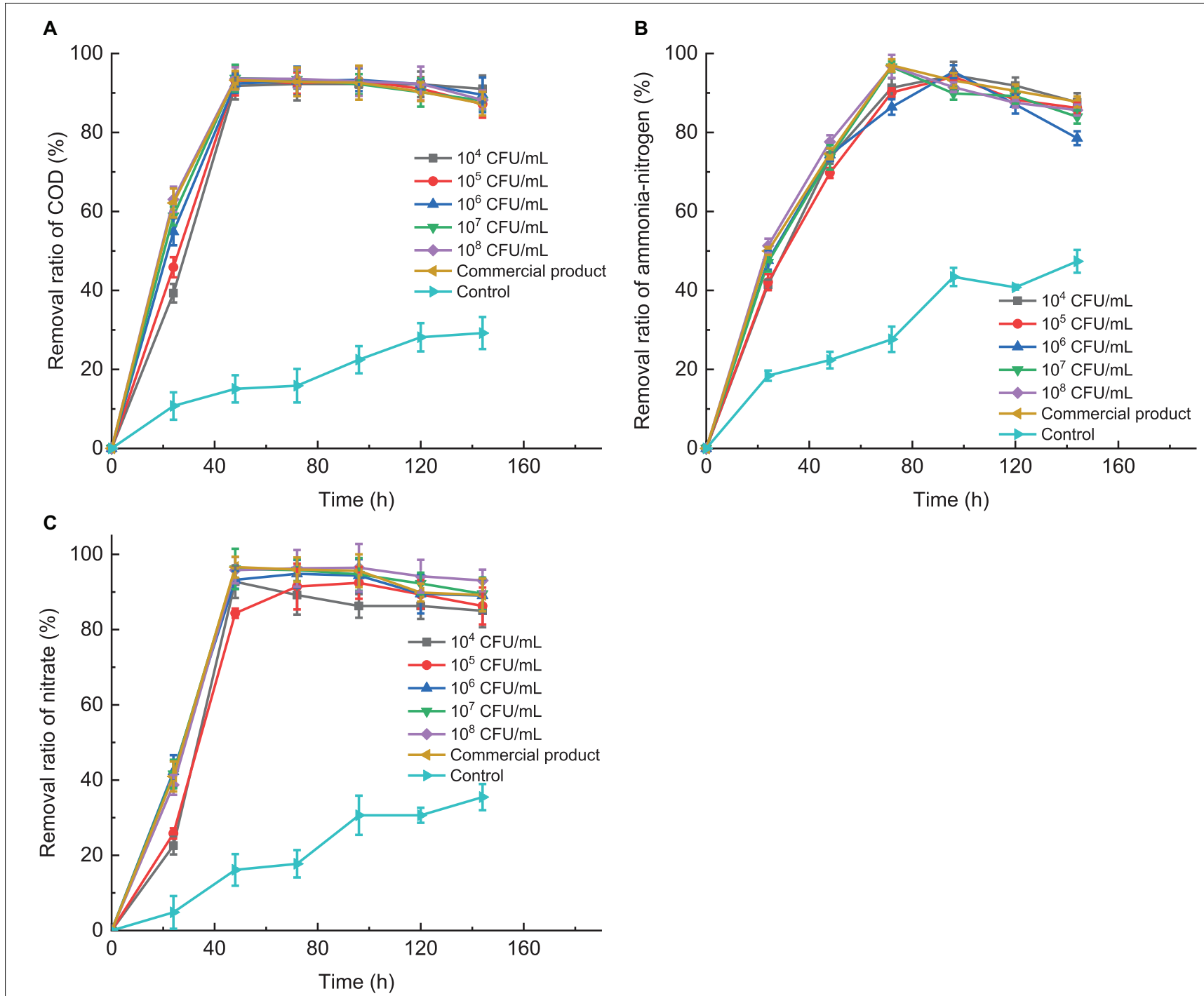

FIGURE 3 | The purification effects of multi-strain tropical Bacillus spp. (B. flexus QG-3, B. flexus NS-4, and B. licheniformis XCG-6 in the proportion 5: 5: 4) on removal ratios of COD (A), ammonia-nitrogen $\mathbf{( B )}$, and nitrate $\mathbf{( C )}$ of artificial feed wastewater. The initial concentrations of multi-strain tropical Bacillus spp. in 10 I artificial feed wastewater were adjusted to $10^{4} \mathrm{CFU} / \mathrm{ml}, 10^{5} \mathrm{CFU} / \mathrm{ml}, 10^{6} \mathrm{CFU} / \mathrm{ml}, 10^{7} \mathrm{CFU} / \mathrm{ml}$, and $10^{8} \mathrm{CFU} / \mathrm{ml}$. Artificial feed wastewater without adding multi-strain tropical Bacillus spp. and with commercial probiotic biocontrol product at $10^{8} \mathrm{CFU} / \mathrm{ml}$ level were as negative control and positive control, respectively.

the removal ratio of multi-waste compounds due to the cooperative interactions between the cocultivated probiotic bacteria. To date, not much attempt has been made to focus on the aquaculture wastewater purification through microbial consortium. Meanwhile, the tropical marine region with unique climate and environmental condition harbors diverse probiotic bacteria with unique metabolic and physiological capabilities, and hence success is greatly dependent on having the right microbes with the capabilities in the right environments for the degradation process to occur (Ren et al., 2018; Ren et al., 2019a,b; Wei et al., 2021). Therefore, the aim of this work was to assemble a bacterial consortium as a potential probiotic biocontrol agent for large-scale enhancement of tropical mariculture water quality because of its more efficiency in the removal of multi-waste compounds in effluent water than single cultures.
In the long-term natural evolution, Hainan has formed a unique tropical microbial community structure, and there are abundant resources of Bacillus spp. that are highly adaptable to the tropical marine environment (Wei et al., 2021). Fortunately, based on the indigenous Bacillus spp. strains isolated from

TABLE 7 | Storage stability of multi-strain tropical Bacillus spp. at room temperature.

\begin{tabular}{lccc}
\hline Time (d) & Viable bacteria (CFU/ml) & Protease activity (U/ml) & pH \\
\hline 0 & $\times 10^{9}$ & $23.47 \pm 0.67$ & $7.2 \pm 0.2$ \\
80 & $\times 10^{9}$ & $17.74 \pm 1.03$ & $6.5 \pm 0.3$ \\
160 & $\times 10^{8}$ & $14.36 \pm 0.71$ & $5.7 \pm 0.2$ \\
240 & $\times 10^{8}$ & $10.28 \pm 1.15$ & $5.7 \pm 0.3$
\end{tabular}



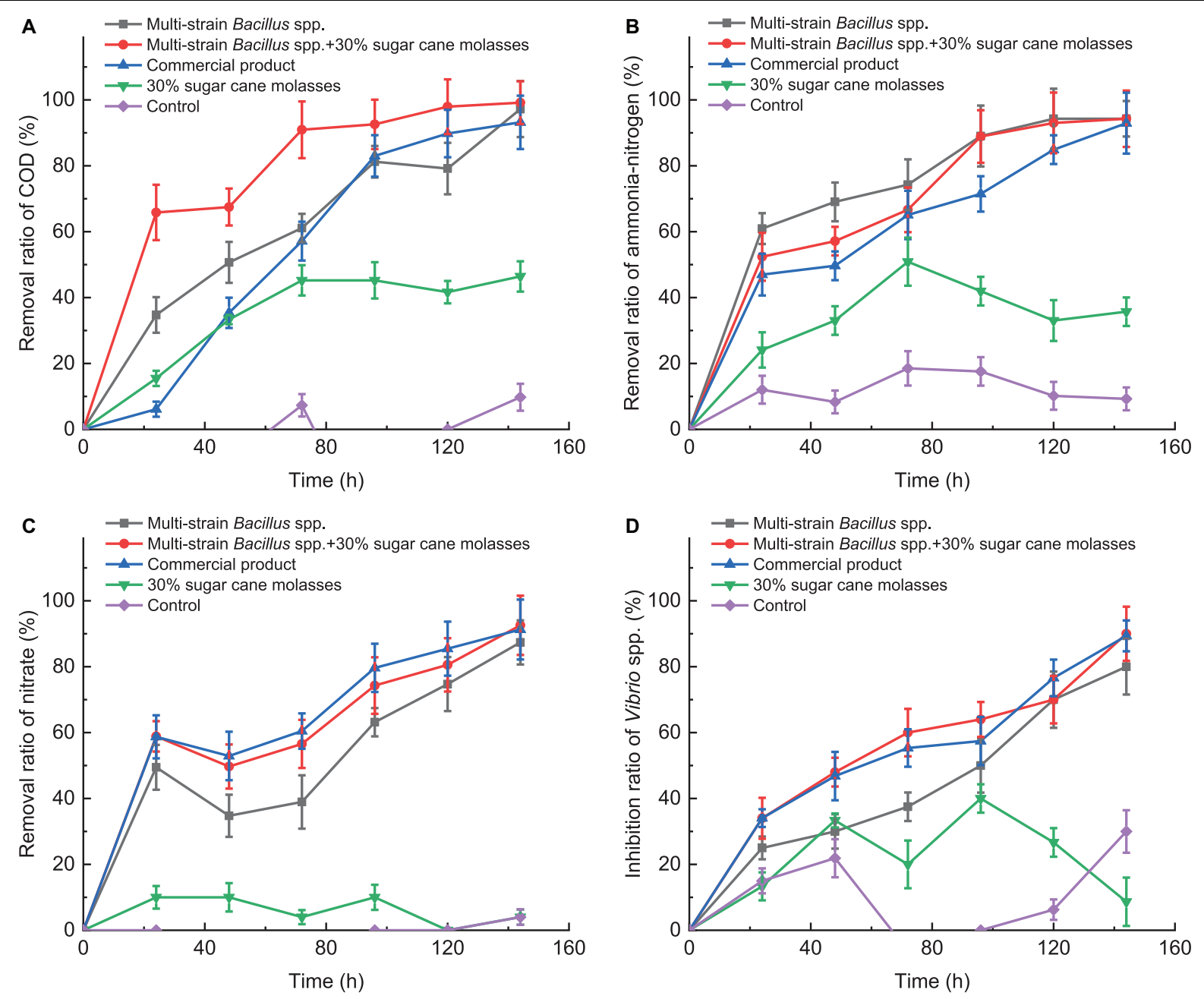

FIGURE 4 | The purification effects of multi-strain tropical Bacillus spp., multi-strain Bacillus spp. + 30\% sugarcane molasses, 30\% sugarcane molasses, commercial probiotic biocontrol product, and control without adding anything on removal ratios of COD (A), ammonia- nitrogen (B), and nitrate (C), and inhibition ratio of Vibrio spp. of aquaculture water of L. vannamei ponds (D). The initial concentrations of multi-strain tropical Bacillus spp. (B. flexus QG-3, B. flexus NS-4, and B. licheniformis XCG-6 with the proportion 5: 5: 4) and commercial probiotic biocontrol product in aquaculture ponds were adjusted to $10^{4}$ CFU/ml.

the tropical mariculture environment in Hainan, the optimum multi-strain Bacillus spp. in theory, $5.17 \times 10^{5} \mathrm{CFU} / \mathrm{ml}$ B. flexus QG-3, $4.79 \times 10^{5} \mathrm{CFU} / \mathrm{ml}$ B. flexus $\mathrm{NS}-4$, and $3.85 \times 10^{5} \mathrm{CFU} / \mathrm{mL}$ B. licheniformis XCG-6, as a potential probiotic agent, were established for artificial feed wastewater purification through optimization in this work.

Given the practical application, the theoretical Bacillus spp. (B. flexus QG-3, B. flexus NS-4, and B. licheniformis XCG-6) proportion of multi-strain tropical species were adjusted to 5 : 5: 4, and artificial feed wastewater and aquaculture ponds were used to confirm their efficiency, which displayed high ability of improvement of mariculture water quality by removing COD, ammonia-nitrogen, and nitrate and significantly inhibited Vibrio spp. at relatively low bacterial concentrations $\left(10^{4} \mathrm{CFU} / \mathrm{ml}\right)$. Moreover, we found that the initial proportion of Bacillus strains in multi-strain tropical Bacillus spp. compared to the initial concentration of multi-strain tropical Bacillus spp. made a more significant effect on the final results of purification effects, whereas the initial concentration of multi-strain tropical Bacillus spp. only affected the purification rate of treatment in the early stage (0-48 h; Figure 3). Reportedly, addition of $10^{8} \mathrm{CFU} / \mathrm{ml} \mathrm{B}$. subtilis directly to the rearing water could maintain the concentrations of nitrite, ammonia, and nitrate ions within the tolerable ranges for shrimp culture (Zokaeifar et al., 2014); addition of $10^{10} \mathrm{CFU} / \mathrm{ml}$ Bacillus probiotics in shrimp aquaculture was associated with significantly reduced levels of ammonia, nitrite, and $\mathrm{pH}$ in accord with the present study (Nimrat et al., 2012). All of these indicated that our multi-strain tropical Bacillus spp. can markedly improve the wastewater quality even at relatively low bacterial concentrations $\left(10^{4} \mathrm{CFU} / \mathrm{ml}\right.$; Figures 3, 4).

COD as an important index is commonly used to measure the total amount of organic matter in water (Li et al., 2018). Reportedly, Bacillus as a COD-degrading bacterial consortium 
can product a variety of digestive enzymes, surfactants, hydrocarbons, phenols, fatty acids, ketones, etc., to accelerate the strong organic matter decomposition as nutrients for its own growth (Arima et al., 1968; Arellano-Carbajal and OlmosSoto, 2002; Gaur and Tiwari, 2015; Barman et al., 2018; Hura et al., 2018; Li et al., 2018). According to our results (Figures 3A, 4A), multi-strain tropical Bacillus spp. as CODdegrading bacterial consortium significantly removed COD in aquaculture wastewater, thereby promoting the virtuous cycle of aquaculture water.

There were many studies on Bacillus mineralizing nitrogenous wastes through nitrification and/or denitrification resulting in the reduction of ammonia, nitrate, and nitrite (Nimrat et al., 2012; Barman et al., 2018; Gao et al., 2018; John et al., 2020). Reportedly, ammonia-nitrogen usually displays two forms in water, ionized $\left(\mathrm{NH}^{4+}\right)$, and unionized $\left(\mathrm{NH}_{3}\right)$, which are both toxic to aquatic animals and easily soluble in the cell membrane, thereby being absorbed by gills (John et al., 2020). Nitrate $\left(\mathrm{NO}^{2-}\right)$ converted from ammonia-nitrogen as the end product of nitrification is negligibly toxic compared to ammonia and nitrite. Denitrification can convert nitrate $\left(\mathrm{NO}^{3-}\right)$ into nitrogen gas $\left(\mathrm{N}_{2}\right)$, thereby removing excessive nitrogen from wastewater ( $\mathrm{Xu}$ et al., 2021). Therefore, we reason that the nitrifying and denitrifying actions of the multistrain tropical Bacillus spp. can in sequence convert ammonianitrogen to nitrite, nitrite to nitrate, and then nitrate to nitrogen gas, thereby resulting in the markable declination of ammonia-nitrogen and nitrate in aquaculture wastewater (Figures 3B,C, 4B,C).

Many Bacillus spp. are important because of their ability to produce antibiotics/metabolites which have antagonistic effects against pathogenic microorganisms (Sun et al., 2010; Abarike et al., 2018; Kuebutornye et al., 2019). Literatures have proven that aquaculture animals with diet supplemented with Bacillus species as probiotics resulted in a better protein efficiency ratio, lower feed conversion ratio, and fast growth (De et al., 2018; Goda et al., 2018; Sadat Hoseini Madani et al., 2018). Nimrat et al. (2012) also reported that forms of Bacillus probiotics and modes of probiotic administration Bacillus probiotics did not affect the growth and survival of shrimp. In this study, the antagonistic action of the multi-strain tropical Bacillus spp. effectively inhibited the pathogenic Vibrio spp. to ensure the health of aquatic animals. Meanwhile, in order to be considered as a probiotic, the strains have to be non-toxic to the host. This multi-strain tropical Bacillus spp. as a potential biological agent was harmless to shrimp as no mortality was observed.

\section{CONCLUSION}

In summary, we reported an efficient multi-strain tropical Bacillus spp. as a potential probiotic biocontrol agent for largescale enhancement of mariculture water quality by gradual optimization and large-scale verification. This multi-strain tropical Bacillus spp. in the optimum proportion 5: 5: 4 of B. flexus QG-3, B. flexus NS-4, and B. licheniformis XCG-6 as a safe biocontrol agent can not only effectively improve the mariculture water quality but also significantly inhibit Vibrio spp. in aquaculture water by COD-degrading, nitrifying, denitrifying, and antagonistic actions. Additionally, the initial Bacillus spp. proportion in this multi-strain biocontrol agent as a main factor markedly affected the final purification effects of wastewater, whereas the initial concentration of this multi-strain biocontrol agent only influenced the purification rates instead of purification effects at the $0-48$-h period. This work will lay a foundation to develop beneficial microbial agents for wastewater purification and construct an eco-friendly tropical aquaculture model for environmental protection. However, the concept of multi-strain tropical Bacillus spp. as a potential probiotic biocontrol agent needs further research to assess the bacterial compositions based on molecular technology, thereby revealing the action mechanisms of the multi-strain Bacillus spp. in order to have further understanding of bacterial interactions for application in mariculture systems.

\section{DATA AVAILABILITY STATEMENT}

The original contributions presented in the study are included in the article/Supplementary Material, further inquiries can be directed to the corresponding author/s.

\section{AUTHOR CONTRIBUTIONS}

WR and ZX designed the study. WR wrote and revised the manuscript. WR, HW, CG, and BX performed the experiments. WR, HL, XZ, XC, and AH analyzed the data. All the authors contributed to the article and approved the submitted version.

\section{FUNDING}

This research was financially supported by the National Key Research and Development Project of China (2019YFD0901304 and 2020YFD0901104), the Key Research and Development Project of Hainan Province (ZDYF2020095), Marine Economic and Innovative Demonstration City Project of State Oceanic Administration (HHCL201802 and HHCL201813), the Foundation of Hainan Agricultural and Rural Department (NY-2019-819), and the Scientific Research Foundation of Hainan University (KYQD(ZR)21005, KYQD(ZR)1967, KYQD(ZR)1819, and KYQD(ZR)20060).

\section{ACKNOWLEDGMENTS}

We are thankful to the reviewers who helped improve this manuscript.

\section{SUPPLEMENTARY MATERIAL}

The Supplementary Material for this article can be found online at: https://www.frontiersin.org/articles/10.3389/fmicb.2021. 699378/full\#supplementary-material 


\section{REFERENCES}

Abarike, E. D., Jian, J., Tang, J., Cai, J., Yu, H., Lihua, C., et al. (2018). Influence of traditional Chinese medicine and Bacillus species (TCMBS) on growth, immune response and disease resistance in Nile tilapia, Oreochromis niloticus. Aquacult. Res. 49, 2366-2375. doi: 10.1111/are.13691

Arellano-Carbajal, F., and Olmos-Soto, J. (2002). Thermostable $\alpha-1,4$-and $\alpha-1$, 6-glucosidase enzymes from Bacillus sp. isolated from a marine environment. World J. Microbiol. Biotechnol. 18, 791-795. doi: 10.1023/A:1020433 210432

Arima, K., Kakinuma, A., and Tamura, G. (1968). Surfactin, a crystalline peptidelipid surfactant produced by Bacillus subtilis: isolation, characterization and its inhibition of fibrin clot formation. Biochem. Biophys. Res. Commun. 31, 488-494. doi: 10.1016/0006-291X(68)90503-2

Asfaram, A., Ghaedi, M., and Goudarzi, A. (2016). Optimization of ultrasoundassisted dispersive solid-phase microextraction based on nanoparticles followed by spectrophotometry for the simultaneous determination of dyes using experimental design. Ultrason. Sonochem. 32, 407-417. doi: 10.1016/j.ultsonch. 2016.04.009

Barman, P., Bandyopadhyay, P., Kati, A., Paul, T., Mandal, A. K., Mondal, K. C., et al. (2018). Characterization and strain improvement of aerobic denitrifying EPS producing bacterium Bacillus cereus PB88 for shrimp water quality management. Waste Biomass Valorization 9, 1319-1330. doi: 10.1007/s12649017-9912-2

Blancheton, J., Attramadal, K., Michaud, L., D’orbcastel, E. R., and Vadstein, O. (2013). Insight into bacterial population in aquaculture systems and its implication. Aquacult. Eng. 53, 30-39. doi: 10.1016/j.aquaeng.2012. 11.009

Boyd, C. E., and Massaut, L. (1999). Risks associated with the use of chemicals in pond aquaculture. Aquacult. Eng. 20, 113-132. doi: 10.1016/S0144-8609(99) 00010-2

Cha, J.-H., Rahimnejad, S., Yang, S.-Y., Kim, K.-W., and Lee, K.-J. (2013). Evaluations of Bacillus spp. as dietary additives on growth performance, innate immunity and disease resistance of olive flounder (Paralichthys olivaceus) against Streptococcus iniae and as water additives. Aquaculture 402, 50-57. doi: 10.1016/j.aquaculture.2013.03.030

Chang, B.-V., Liao, C.-S., Chang, Y.-T., Chao, W.-L., Yeh, S.-L., Kuo, D.L., et al. (2019). Investigation of a farm-scale multitrophic recirculating aquaculture system with the addition of rhodovulum sulfidophilum for Milkfish (Chanos chanos) coastal aquaculture. Sustainability 11:1880. doi: 10.3390/su110 71880

Dash, P., Avunje, S., Tandel, R. S., Sandeep, K. P., and Panigrahi, A. (2017). Biocontrol of Luminous Vibriosis in Shrimp Aquaculture: A Review of Current Approaches and Future Perspectives. Rev. Fisher. Sci. Aquacult. 25, 245-255. doi: 10.1080/23308249.2016.1277973

Dawood, M. A., Moustafa, E. M., Gewaily, M. S., Abdo, S. E., Abdel-Kader, M. F., Saadallah, M. S., et al. (2020). Ameliorative effects of Lactobacillus plantarum L-137 on Nile tilapia (Oreochromis niloticus) exposed to deltamethrin toxicity in rearing water. Aquat. Toxicol. 219:105377. doi: 10.1016/j.aquatox.2019.1 05377

De, D., Ananda Raja, R., Ghoshal, T. K., Mukherjee, S., and Vijayan, K. K. (2018). Evaluation of growth, feed utilization efficiency and immune parameters in tiger shrimp (Penaeus monodon) fed diets supplemented with or diet fermented with gut bacterium Bacillus sp. DDKRC1. isolated from gut of Asian seabass (Lates calcarifer). Aquacult. Res. 49, 2147-2155. doi: 10.1111/are.1 3669

El Aamri, L., Hafidi, M., Scordino, F., Krasowska, A., Lebrihi, A., Orlando, M. G., et al. (2020). Arthrographis curvata and Rhodosporidium babjevae as New Potential Fungal Lipase Producers for Biotechnological Applications. Braz. Arch. Biol. Tech. 63:2020180444. doi: 10.1590/1678-4324-2020 180444

Gao, F., Liao, S., Liu, S., Bai, H., Wang, A., and Ye, J. (2019). The combination use of Candida tropicalis HH8 and Pseudomonas stutzeri LZX301 on nitrogen removal, biofloc formation and microbial communities in aquaculture. Aquaculture 500, 50-56. doi: 10.1016/j.aquaculture.2018.09.041

Gao, J., Gao, D., Liu, H., Cai, J., Zhang, J., and Qi, Z. (2018). Biopotentiality of High Efficient Aerobic Denitrifier Bacillus megaterium S379 for Intensive
Aquaculture Water Quality Management. J. Environ. Manage. 222, 104-111. doi: 10.1016/j.jenvman.2018.05.073

Gaur, R., and Tiwari, S. (2015). Isolation, production, purification and characterization of an organic-solvent-thermostable alkalophilic cellulase from Bacillus vallismortis RG-07. BMC Biotech. 15:19. doi: 10.1186/s12896-0150129-9

Goda, A., Omar, E., Srour, T., Kotiet, A., El-Haroun, E., and Davies, S. J. (2018). Effect of diets supplemented with feed additives on growth, feed utilization, survival, body composition and intestinal bacterial load of early weaning European seabass, Dicentrarchus labrax post-larvae. Aquacult. Int. 26, 169-183. doi: 10.1007/s10499-017-0200-8

Guo, H., Xian, J.-A., and Wang, A. L. (2016). Analysis of digital gene expression profiling in hemocytes of white shrimp Litopenaeus vannamei under nitrite stress. Fish Shellfish Immunol. 56, 1-11. doi: 10.1016/j.fsi.2016 .06 .059

Hai, N. (2015). The use of probiotics in aquaculture. J. Appl. Microbiol. 119, 917-935. doi: 10.1111/jam.12886

Hamza, F., Satpute, S., Banpurkar, A., Kumar, A.R., and Zinjarde, S. (2017). Biosurfactant from a marine bacterium disrupts biofilms of pathogenic bacteria in a tropical aquaculture system. FEMS Microbiol. Ecol. 93, fix140. doi: 10.1093/femsec/fix140

Hucheng, J., Xiaohui, C., Wenji, B., Longlong, F., Qin, Q., Liqiang, Z., et al. (2020). Comparison of bacterial communities in channel catfish Ictalurus punctatus culture ponds of an industrial ecological purification recirculating aquaculture system. Aquacult. Res. 51, 2432-2442. doi: 10.1111/are. 14587

Hura, M. U. D., Zafar, T., Borana, K., Prasad, J. R., and Iqbal, J. (2018), Effect of commercial probiotic Bacillus megaterium on water quality in composite culture of major carps. Int. J. Curr. Agric. Sci. 8, 268-273.

John, E. M., Krishnapriya, K., and Sankar, T. V. (2020). Treatment of ammonia and nitrite in aquaculture wastewater by an assembled bacterial consortium. Aquaculture 526:735390. doi: 10.1016/j.aquaculture.2020. 735390

Kesarcodi-Watson, A., Kaspar, H., Lategan, M. J., and Gibson, L. (2012). Performance of single and multi-strain probiotics during hatchery production of Greenshell ${ }^{\mathrm{TM}}$ mussel larvae, Perna canaliculus. Aquaculture 354, 56-63. doi: 10.1016/j.aquaculture.2012.04.026

Kuebutornye, F. K., Abarike, E. D., and Lu, Y. (2019). A review on the application of Bacillus as probiotics in aquaculture. Fish Shellfish Immunol. 87, 820-828. doi: 10.1016/j.fsi.2019.02.010

Kuhn, D. D., Smith, S. A., Boardman, G. D., Angier, M. W., Marsh, L., and Flick, G. J. Jr. (2010). Chronic toxicity of nitrate to Pacific white shrimp, Litopenaeus vannamei: Impacts on survival, growth, antennae length, and pathology. Aquaculture 309, 109-114. doi: 10.1016/j.aquaculture.2010 .09 .014

Kumari, V., Yadav, A., Haq, I., Kumar, S., Bharagava, R. N., Singh, S. K., et al. (2016). Genotoxicity evaluation of tannery effluent treated with newly isolated hexavalent chromium reducing Bacillus cereus. J. Environ. Manage. 183, 204211. doi: 10.1016/j.jenvman.2016.08.017

Lalloo, R., Moonsamy, G., Ramchuran, S., Goergens, J., and Gardiner, N. (2010). Competitive exclusion as a mode of action of a novel Bacillus cereus aquaculture biological agent. Lett. Appl. Microbiol. 50, 563-570. doi: 10.1111/j.1472-765X. 2010.02829.x

Lalloo, R., Ramchuran, S., Ramduth, D., Gorgens, J., and Gardiner, N. (2007). Isolation and selection of Bacillus spp. as potential biological agents for enhancement of water quality in culture of ornamental fish. J. Appl. Microbiol. 103, 1471-1479. doi: 10.1111/j.1365-2672.2007.03 360.x

Li, W., Jia, M.-X., Deng, J., Wang, J.-H., Lin, Q.-L., Liu, C., et al. (2018). Isolation, genetic identification and degradation characteristics of CODdegrading bacterial strain in slaughter wastewater. Saudi J. Biol. Sci. 25, 1800-1805. doi: 10.1016/j.sjbs.2018.08.022

Li, Y., Wang, L., Yan, Z., Chao, C., Yu, H., Yu, D., et al. (2020). Effectiveness of dredging on internal phosphorus loading in a typical aquacultural lake. Sci. Total Environ. 744, 140883-140883. doi: 10.1016/j.scitotenv.2020.1 40883 
Lin, Y. C., and Chen, J. C. (2001). Acute toxicity of ammonia on Litopenaeus vannamei Boone juveniles at different salinity levels. J. Exp. Mar. Biol. Ecol. 259, 109-119. doi: 10.1016/S0022-0981(01)00227-1

Lin, Y.-C., and Chen, J.-C. (2003). Acute toxicity of nitrite on Litopenaeus vannamei (Boone) juveniles at different salinity levels. Aquaculture 224, 193 201. doi: 10.1016/S0044-8486(03)00220-5

Lu, H., Zhang, G., Zheng, Z., Meng, F., Du, T., and He, S. (2019). Bio-conversion of photosynthetic bacteria from non-toxic wastewater to realize wastewater treatment and bioresource recovery: a review. Bioresour. Technol. 278, 383-399. doi: 10.1016/j.biortech.2019.01.070

Luo, L., Zhao, Z., Huang, X., Du, X., Wang, C. A., Li, J., et al. (2016). Isolation, Identification, and Optimization of Culture Conditions of a BioflocculantProducing Bacterium Bacillus megaterium SP1 and Its Application in Aquaculture Wastewater Treatment. Biomed Res. Int. 2016:2758168. doi: 10. $1155 / 2016 / 2758168$

Ma, C.-W., Cho, Y.-S., and Oh, K.-H. (2009). Removal of pathogenic bacteria and nitrogens by Lactobacillus spp. JK-8 and JK-11. Aquaculture 287, 266-270. doi: 10.1016/j.aquaculture.2008.10.061

Mariane De Morais, A. P., Abreu, P. C., Wasielesky, W., and Krummenauer, D. (2020). Effect of aeration intensity on the biofilm nitrification process during the production of the white shrimp Litopenaeus vannamei (Boone, 1931) in Biofloc and clear water systems. Aquaculture 514:734516. doi: 10.1016/j.aquaculture. 2019.734516

Moriarty, D. J. (1997). The role of microorganisms in aquaculture ponds. Aquaculture 151, 333-349. doi: 10.1016/S0044-8486(96) 01487-1

Muhamad, M. H., Abdullah, S. R. S., Mohamad, A. B., Rahman, R. A., and Kadhum, A. A. H. (2013). Application of response surface methodology (RSM) for optimisation of $\mathrm{COD}, \mathrm{NH} 3-\mathrm{N}$ and 2, 4-DCP removal from recycled paper wastewater in a pilot-scale granular activated carbon sequencing batch biofilm reactor (GAC-SBBR). J. Environ. Manage. 121, 179-190. doi: 10.1016/j. jenvman.2013.02.016

Nimrat, S., Suksawat, S., Boonthai, T., and Vuthiphandchai, V. (2012). Potential Bacillus probiotics enhance bacterial numbers, water quality and growth during early development of white shrimp (Litopenaeus vannamei). Vet. Microbiol. 159, 443-450. doi: 10.1016/j.vetmic.2012.04.029

Nygren, C. M. R., Edqvist, J., Elfstrand, M., Heller, G., and Taylor, A. F. S. (2007). Detection of extracellular protease activity in different species and genera of ectomycorrhizal fungi. Mycorrhiza 17, 241-248. doi: 10.1007/s00572-0060100-7

Paopradit, P., Tansila, N., Surachat, K., and Mittraparp-Arthorn, P. (2021). Vibrio alginolyticus influences quorum sensing-controlled phenotypes of acute hepatopancreatic necrosis disease-causing Vibrio parahaemolyticus. Peerj 9:11567. doi: $10.7717 /$ peerj.11567

Ren, W., Cai, R., Yan, W., Lyu, M., Fang, Y., and Wang, S. (2018). Purification and characterization of a biofilm-degradable dextranase from a marine bacterium. Mar. Drugs 16:51. doi: 10.3390/md16020051

Ren, W., Ding, Y., Gu, L., Yan, W., Wang, C., Lyu, M., et al. (2019a). Characterization and mechanism of the effects of $\mathrm{Mg}-\mathrm{Fe}$ layered double hydroxide nanoparticles on a marine bacterium: new insights from genomic and transcriptional analyses. Biotechnol. Biofuels 12:196. doi: 10.1186/s13068019-1528-2

Ren, W., Liu, L., Gu, L., Yan, W., Feng, Y. L., Dong, D., et al. (2019b). Crystal Structure of GH49 Dextranase from Arthrobacter oxidans KQ11: Identification of Catalytic Base and Improvement of Thermostability Using Semirational Design Based on B-Factors. J. Agr. Food. Chem. 67, 4355-4366. doi: 10.1021/ acs.jafc.9b01290

Ren, W., Wang, S., Lü, M., Wang, X., Fang, Y., Jiao, Y., et al. (2016). Optimization of four types of antimicrobial agents to increase the inhibitory ability of marine Arthrobacter oxydans KQ11 dextranase mouthwash. Chin. J. Oceanol. Limnol. 34, 354-366. doi: 10.1007/s00343-015-4376-3

Rengpipat, S., Phianphak, W., Piyatiratitivorakul, S., and Menasveta, P. (1998). Effects of a probiotic bacterium on black tiger shrimp Penaeus monodon survival and growth. Aquaculture 167, 301-313. doi: 10.1016/S0044-8486(98) 00305-6

Ruan, Y., Taherzadeh, M. J., Kong, D., Lu, H., Zhao, H., Xu, X., et al. (2020). Nitrogen removal performance and metabolic pathways analysis of a novel aerobic denitrifying halotolerant Pseudomonas balearica strain RAD-17. Microorganisms 8:72. doi: 10.3390/microorganisms80 10072

Sadat Hoseini Madani, N., Adorian, T. J., Ghafari Farsani, H., and Hoseinifar, S. H. (2018). The effects of dietary probiotic Bacilli (Bacillus subtilis and Bacillus licheniformis) on growth performance, feed efficiency, body composition and immune parameters of whiteleg shrimp (Litopenaeus vannamei) postlarvae. Aquacult. Res. 49, 1926-1933. doi: 10.1111/are. 13648

Saravanan, M., Barik, S. K., Mubarakali, D., Prakash, P., and Pugazhendhi, A. (2018). Synthesis of silver nanoparticles from Bacillus brevis (NCIM 2533) and their antibacterial activity against pathogenic bacteria. Microb. Pathogenesis 116, 221-226. doi: 10.1016/j.micpath.2018 .01 .038

Shah, A., Favaro, L., Alibardi, L., Cagnin, L., Sandon, A., Cossu, R., et al. (2016). Bacillus sp. strains to produce bio-hydrogen from the organic fraction of municipal solid waste. Appl. Energy 176, 116-124. doi: 10.1016/j.apenergy.2016. 05.054

Sonune, N., and Garode, A. (2018). Isolation, characterization and identification of extracellular enzyme producer Bacillus licheniformis from municipal wastewater and evaluation of their biodegradability. Biotechnol. Res. Inno. 2, 37-44. doi: 10.1016/j.biori.2018.03.001

Sun, Y.-Z., Yang, H.-L., Ma, R.-L., and Lin, W.-Y. (2010). Probiotic applications of two dominant gut Bacillus strains with antagonistic activity improved the growth performance and immune responses of grouper Epinephelus coioides. Fish Shellfish Immunol. 29, 803-809. doi: 10.1016/j.fsi.2010. 07.018

Thurlow, C. M., Williams, M. A., Carrias, A., Ran, C., Newman, M., Tweedie, J., et al. (2019). Bacillus velezensis AP193 exerts probiotic effects in channel catfish (Ictalurus punctatus) and reduces aquaculture pond eutrophication. Aquaculture 503, 347-356. doi: 10.1016/j.aquaculture.2018 .11 .051

Timmerman, H., Koning, C., Mulder, L., Rombouts, F., and Beynen, A. (2004). Monostrain, multistrain and multispecies probiotics-a comparison of functionality and efficacy. Int. J. Food Microbiol. 96, 219-233. doi: 10.1016/j. ijfoodmicro.2004.05.012

Van Hai, N., Fotedar, R., and Buller, N. (2007). Selection of probiotics by various inhibition test methods for use in the culture of western king prawns, Penaeus latisulcatus (Kishinouye). Aquaculture 272, 231-239. doi: 10.1016/j. aquaculture.2007.07.223

Vaseeharan, B., and Ramasamy, P. (2003). Control of pathogenic Vibrio spp. by Bacillus subtilis BT23, a possible probiotic treatment for black tiger shrimp Penaeus monodon. Lett. Appl. Microbiol. 36, 83-87. doi: 10.1046/j.1472-765X. 2003.01255.x

Venkataraghavan, R., Thiruchelvi, R., and Sharmila, D. (2020). Statistical optimization of textile dye effluent adsorption by Gracilaria edulis using Plackett-Burman design and response surface methodology. Heliyon 6:e05219. doi: 10.1016/j.heliyon.2020.e05219

Verschuere, L., Rombaut, G., Sorgeloos, P., and Verstraete, W. (2000). Probiotic bacteria as biological control agents in aquaculture. Microbiol. Mol. Biol. Rev. 64, 655-671. doi: 10.1023/A:1024127 100993

Vi, L. V. T., Salakkam, A., and Reungsang, A. (2017). Optimization of key factors affecting bio-hydrogen production from sweet potato starch. Energy Procedia 138, 973-978. doi: 10.1016/j.egypro.2017.10.092

Wang, Y., Bi, L., Liao, Y., Lu, D., Zhang, H., Liao, X., et al. (2019). Influence and characteristics of Bacillus stearothermophilus in ammonia reduction during layer manure composting. Ecotox. Environ. Safe. 180, 80-87. doi: 10.1016/j. ecoenv.2019.04.066

Wei, Y., Bu, J., Long, H., Zhang, X., Cai, X., Huang, A., et al. (2021). Community structure of protease-producing bacteria cultivated from aquaculture systems: Potential impact of a tropical environment. Front. Microbiol. 12:638129. doi: 10.3389/fmicb.2021.638129

Xu, Y., Lu, J., Huang, S., and Zhao, J. (2021). Submerged plants alleviated the impacts of increased ammonium pollution on anammox bacteria and nirS denitrifiers in the rhizosphere. Environ. Sci. Pollut. Res. Int. 2021, 14715-14717. doi: 10.1007/s11356-021-14715-7

Yi, Y., Zhang, Z., Zhao, F., Liu, H., Yu, L., Zha, J., et al. (2018). Probiotic potential of Bacillus velezensis JW: antimicrobial activity against fish pathogenic bacteria 
and immune enhancement effects on Carassius auratus. Fish Shellfish Immunol. 78, 322-330. doi: 10.1016/j.fsi.2018.04.055

Zhang, M., Li, A., Yao, Q., Wu, Q., and Zhu, H. (2020). Nitrogen removal characteristics of a versatile heterotrophic nitrifying-aerobic denitrifying bacterium, Pseudomonas bauzanensis DN13-1, isolated from deep-sea sediment. Bioresour. Technol. 305:122626. doi: 10.1016/j.biortech.2019.1 22626

Zheng, X., Duan, Y., Dong, H., and Zhang, J. (2020). The effect of Lactobacillus plantarum administration on the intestinal microbiota of whiteleg shrimp Penaeus vannamei. Aquaculture 2020:735331. doi: 10.1016/j.aquaculture.2020. 735331

Zokaeifar, H., Babaei, N., Saad, C. R., Kamarudin, M. S., Sijam, K., and Balcazar, J. L. (2014). Administration of Bacillus subtilis strains in the rearing water enhances the water quality, growth performance, immune response, and resistance against Vibrio harveyi infection in juvenile white shrimp, Litopenaeus vannamei. Fish Shellfish Immunol. 36, 68-74. doi: 10.1016/j.fsi.201 3.10 .007
Conflict of Interest: The authors declare that the research was conducted in the absence of any commercial or financial relationships that could be construed as a potential conflict of interest.

Publisher's Note: All claims expressed in this article are solely those of the authors and do not necessarily represent those of their affiliated organizations, or those of the publisher, the editors and the reviewers. Any product that may be evaluated in this article, or claim that may be made by its manufacturer, is not guaranteed or endorsed by the publisher.

Copyright (C) 2021 Ren, Wu, Guo, Xue, Long, Zhang, Cai, Huang and Xie. This is an open-access article distributed under the terms of the Creative Commons Attribution License (CC BY). The use, distribution or reproduction in other forums is permitted, provided the original author(s) and the copyright owner(s) are credited and that the original publication in this journal is cited, in accordance with accepted academic practice. No use, distribution or reproduction is permitted which does not comply with these terms. 